\title{
Probabilistic Life-Cycle Cost-Benefit Analysis of Portfolios of Buildings under Flood
}

\section{Hazard}

\author{
You Dong $^{1}$ and Dan M. Frangopol ${ }^{2 *}$
}

\begin{abstract}
:
Nowadays, the number of residential buildings in flood prone zones is increasing significantly. Therefore, for these buildings, it is of vital importance to apply hazard risk mitigation strategies. In this paper, probabilistic cost-benefit analysis of flood risk mitigation strategies for portfolios of residential buildings is performed in a life-cycle context. Additionally, an efficient methodology is proposed to aid decision-makers on whether or not to retrofit portfolios of structures considering both expected and standard deviation of life-cycle cost. The vulnerability model of buildings under flood hazard is introduced considering serviceability and ultimate limit states. Probabilistic cost-benefit analysis is performed by comparing the effectiveness of different retrofit actions. Additionally, uncertainty and correlation effects are considered in the probabilistic loss and cost-benefit analysis procedures. The proposed approach is applied to a portfolio of residential buildings located in Florida to illustrate its capacity and application. However, the proposed approach is general and can be applied to buildings located in other regions.
\end{abstract}

Key words: Flood; Portfolio of buildings; Regional risk; Probabilistic cost-benefit analysis; Uncertainty; Correlation; Life-cycle

\footnotetext{
${ }^{1}$ Assistant Professor of Structural Engineering, Department of Civil and Environmental Engineering, The Hong Kong Polytechnic University, Hung Hom, Kowloon, Hong Kong, you.dong@ polyu.edu.hk.

${ }^{2}$ Professor and the Fazlur R. Khan Endowed Chair of Structural Engineering and Architecture, Department of Civil and Environmental Engineering, Engineering Research Center for Advanced Technology for Large Structural Systems (ATLSS Center), Lehigh University, 117 ATLSS Dr., Bethlehem, PA 18015-4729, USA, dan.frangopol@lehigh.edu, *Corresponding Author.
} 


\section{Introduction}

Typically, flood causes include long-lasting rainfall, snowmelt, dam break, and temporary sealevel rise [1]. Flood accounts for almost $30 \%$ of the global losses associated with natural hazards $[2 ; 3]$. Due to the catastrophic losses to the people and assets, flood is considered one of the major natural hazards for the society and economy in the United States and many other countries. Due to the effects of global warming and climate change, the frequency, intensity, and magnitude of flood are increasing. Buildings play an important role in the economy and their damages resulting from a flood event contribute significantly to the total community loss. Furthermore, due to the rapid urbanization and population growth, buildings have an increasing exposure to flood in the urban areas. Thus, an effective probabilistic assessment and hazard mitigation approach for building portfolios is needed to estimate and optimize the performance of buildings under floods at a large scale in a life-cycle perspective. This paper aims to propose a novel approach to aid the flood hazard mitigation of portfolios of residential buildings considering the uncertainty and correlation effects. To the best knowledge of the authors, there have been no studies to address this issue. The presented approach can aid the flood hazard mitigation and risk management of building portfolios at a large scale.

Nowadays, performance-based engineering (PBE) is developing rapidly and is applied to investigate the performance of infrastructure under hazard effects $[4 ; 5 ; 6 ; 7]$. Relevant studies to incorporate PBE within structural design code are still needed. In this paper, the PBE approach is adopted within performance assessment and mitigation of building portfolios imposed to flood hazard. Generally, the performance-based assessment can be divided into three parts: (a) hazard scenarios analysis, (b) structural performance and damage assessment, and (c) consequence and loss evaluation associated with decision variables (e.g., repair loss, downtime, and fatalities). In 
this study, PBE is adopted to investigate the performance of portfolios of buildings under flood effects.

The performance of a building under a flood event depends on many parameters, such as wall thickness, height of the building, presence of barriers, dimensions and configuration of doors and windows, and height of the raised foundation [8]. The damage mechanisms of buildings under flood effects include physical and chemical deterioration, structural failure of walls or windows, and scour of foundation. The building performance also depends on the characteristics of floods (e.g., duration, frequency, and magnitude). Most vulnerability analyses under a flood event consider the flood depth as the main factor [9; 10]. Although flood depth is the most common factor considered in the damage assessment, the flood velocity also has a significant effect on the structural failure [11]. In this work, both flood depth and velocity are considered in the structural vulnerability analysis. Roos [12] developed damage curves of residential buildings considering the failure of walls and scour of the foundation under the hydrostatic and hydrodynamic pressures, wave actions, and pounding debris. Both the flood depth and velocity were considered within the damage assessment procedure; Kelman [13] presented an approach for the vulnerability assessment of residential buildings at a component level (e.g., wall and window) considering both flood rise and water infiltration processes; Mazzorana et al. [14] developed a method to quantify vulnerability of buildings by modeling the process intensity, the impact on the element, and the physical response of the building envelope; and Custer and Nishijima [15] proposed an approach for the flood vulnerability model considering relevant hazard and building characteristics at both component and system levels. All these studies investigated the performance of a single building under flood effects. To the best knowledge of the authors, there are no studies available focused on the performance and loss 
assessment of portfolios of buildings in a systematic manner; thus, relevant studies are needed. This paper aims to provide an approach to aid the assessment of portfolios of buildings under flood effects by considering both the correlation and uncertainty effects.

Certainly, there are uncertainties associated with hazard intensity, structural performance, and consequences of structural systems under flood effects. Accordingly, a probabilistic approach is needed to account for different types of uncertainties. Under a given flood event, there are uncertainties with respect to the hazard intensity in terms of depth and velocity at the locations of buildings. In this paper, a probabilistic risk assessment and mitigation approach is developed to compute the loss of portfolios of buildings in a life-cycle context. As the flood is a low-probability high-consequence event during the service life of infrastructure, it is reasonable to investigate the flood effects on buildings within a large time interval, such as the life-cycle. Therefore, the life-cycle concept should be incorporated within decision making process of retrofit actions of portfolios of residential buildings under the flood. Additionally, since the buildings within a portfolio may be constructed by the same company using materials and specifications, there exist correlations among these buildings. Also, the hazard intensities at the locations of the buildings are also correlated as they all arise from the same investigated flood event. Probabilistic loss of portfolios of buildings under flood effects at a large scale considering uncertainties and correlation effects has not been considered in previous studies. Herein, in order to quantify the probabilistic regional loss of portfolios of buildings, the uncertainties and correlation effects are incorporated within the evaluation procedure. Both mean and standard deviation are computed in the assessment process considering uncertainty and correlation effects.

Cost-benefit analysis should be incorporated into the hazard mitigation process in a probabilistic manner. The majority of the previous studies emphasized on the expected value of 
benefit and did not consider the uncertainty related to benefit analysis, which may lead to inappropriate decisions. As there are large uncertainties associated with the hazard occurrence and intensity, these uncertainties should be incorporated within the benefit-cost analysis. Thus, the benefit-cost ratio should be treated as a random variable instead of a deterministic value. The benefit associated with a specific retrofit plan depends on the intensity and frequency of the investigated hazard, time interval considered, and the structural performance under retrofit actions. To the best knowledge of the authors, there are no studies available incorporating all relevant uncertainties within the benefit-cost analysis of infrastructure at a large scale. Herein, the uncertainties associated with benefit are considered in the hazard risk mitigation procedure at a community level. Furthermore, the life-cycle concept is adopted to investigate buildings' performance and benefit-cost ratio of retrofit actions.

Overall, this paper aims to provide an efficient probabilistic framework to aid the flood hazard risk mitigation of portfolios of residential buildings considering the probabilistic flood scenarios, building's performance, and benefit-cost analysis. The proposed probabilistic framework is general and can be applied to any portfolios of buildings. In this study, it is applied to unreinforced masonry buildings, one of the most common residential building types.

\section{Building Damage Assessment under Flood}

In order to assess the structural performance of buildings under flood effects, a framework that considers hazard intensity and occurrence frequency, structural vulnerability under hazard, and consequence evaluation should be established. The flowchart regarding the performance-based hazard loss assessment is shown in Figure 1. 


\section{Flood Scenarios}

The first step is to identify the magnitude and intensity of the flood. The PBE assessment of buildings under a flood event involves many parameters. The most critical parameters are the flood factors (e.g., depth and velocity) and the building properties. Thus, in order to compute the structural performance, the flood depth and velocity should be identified first. The peak flow associated with different return periods of the flood can be determined based on the historical data. Given the flood scenario model, together with the topographic map of the investigated region of interest, the hazard intensity associated with the water height and velocity for a given return period can be obtained and incorporated within the structural performance assessment and hazard management process. This information, together with the detailed cartography of the investigated area and a digital elevation model is used as input into the hydraulic model. The characteristics of the flood can be used for the flood load and structural performance analysis. In this paper, the load effects of the flood on residential buildings are related with flood depth, velocity, and debris considering different limit states. The Poisson process, which has been applied widely in the modeling the number of occurrence of floods within a specific time or space interval $[16 ; 17]$, can be adopted to evaluate the probability of occurrence of the flood.

\section{Load Effects}

The flood effects on buildings include hydrostatic forces, hydrodynamic forces, and forces generated by the impact of debris. The lateral hydrostatic pressure $P_{s}$ and hydrostatic force per unit of length $F_{s}$ could be computed as $[13 ; 18]$

$$
\begin{gathered}
P_{s}=\rho_{w} g h \\
F_{s}=\frac{1}{2} P_{s} h
\end{gathered}
$$


where $g$ is gravity acceleration $\left(\mathrm{m} / \mathrm{s}^{2}\right)$; $\rho_{w}$ is mass density of water $\left(\mathrm{kg} / \mathrm{m}^{3}\right)$; and $h$ is the flood depth difference between the water inside and outside the building $(m)$. The hydrostatic force could be computed as an equivalent point force at the height of $h / 3$ from the ground.

The hydrodynamic load is related to the moving water and is assessed considering the velocity of flood water. The hydrodynamic pressure $P_{d}$ and hydrodynamic force per unit of length $F_{d}$ are

$$
\begin{gathered}
P_{d}=C_{d r a g} \rho_{w} \frac{V^{2}}{2} \\
F_{d}=P_{d} h
\end{gathered}
$$

where $C_{d r a g}$ is drag coefficient and $V$ is average velocity of flood water $(\mathrm{m} / \mathrm{s})$. The structural analysis of the wall under the flood effects is conducted based on Roos [12]. Given the hydrostatic and hydrodynamic pressures, the bending moment of the wall under the loading scenario can be calculated.

The debris effect on the building is also considered in the loading effect evaluation procedure. The debris is carried along the flood and cause damage by crashing into the buildings. The debris sources could be identified based on the observation of the building site and urban planning documents. The structural damage subjected to debris usually depends on the weight of the debris and the flow velocity. The debris force can be computed as [12]

$$
\begin{gathered}
F_{d e}=V_{d e} \sqrt{m_{d e} k_{s}} \\
\frac{1}{k_{s}}=\frac{1}{k_{w a}}+\frac{1}{k_{d e}}
\end{gathered}
$$

where $m_{d e}$ is the debris mass $(k g) ; V_{d e}$ is the velocity of the debris $(\mathrm{m} / \mathrm{s}) ; k_{s}$ is the spring stiffness; $k_{w a}$ is the spring stiffness of wall; and $k_{d e}$ is the spring stiffness of debris. This model is applied to single residential buildings. The force of debris on buildings depends on many factors, such as 
the weight of the debris, velocity of the water, and the materials of the debris and walls. Given the Young's modulus, surface area, and length, stiffness of the debris can be computed. Also, given the mechanics scheme of the wall (e.g., boundary condition, moment of inertia), the stiffness of the wall can be obtained. More detailed information could be found in Roos [12]. Wall failure is one of the most failure mechanisms of the low-rise residential buildings [12]. This failure mode is considered herein.

\section{Damage Analysis}

The mechanical failure of the building under a flood event is emphasized in this section. Walls, acting as both structural and envelop components in the building, have significant importance and their failure can potentially result in the partial or total collapse of the building. Based on [12], the failure mechanism associated with wall failure is the most significant failure model for the masonry and concrete buildings. Thus, the wall failure is of great importance regarding building performance under flood and is emphasized in this section. The failure mechanism of the wall, as the main failure mode of buildings under flood, is emphasized in this paper. The scour of the foundation is not considered in this study, as it is only relevant under very particular situations, such as a high velocity and a water-tight building envelope. The vulnerability analysis of masonry wall can be assessed using different methods, such as finite element analysis [19; 20], yielding line analysis $[21 ; 22]$, and structural analysis [12]. The structural performance analysis represents the structural vulnerability under the given limit state. Given the performance functions and flood scenario, the probabilities associated with different limit states could be

estimated. The probability of failure under flood could be computed using Monte Carlo simulation and/or first/second order reliability methods. The reliability and vulnerability analyses 
incorporate uncertainties associated with structural capacity and load effects associated with flood.

\section{Loss and Life-Cycle Cost Assessment}

\section{Single Building Loss}

The damage loss in monetary terms is investigated in this section. Given the limit states of the building under flood, the probability of the building being in different damage states including failure could be computed. Based on the theorem of total probability, the hazard loss is the sum of consequences weighted with the probabilities of having these consequences. The expected annual loss of the building $i$ under the occurrence of the given hazard can be computed as [23]

$$
l_{i}=\sum_{D S} C_{b i} \cdot r_{c r \mid D S} \cdot P_{D S \mid H}
$$

where $C_{b i}$ is the investigated building cost; $r_{c r \mid D S}$ is the repair cost ratio associated with a damage state $D S$; and $P_{D S \mid H}$ is the conditional probability of a damage state given a flood event. Given the flood intensity (e.g., depth and velocity) associated with different flood intervals, the performance of the building (e.g., probability of being in different damage states) could be computed. The repair loss, related to the flood induced structural damage, is emphasized herein. The repair cost of a building can be calculated as a function of the percentage of total cost, which depends on local labor cost, availability of materials, and local construction practices. Indirect cost could also be incorporated within the consequence evaluation procedure. Loss data from insurance companies can be used to derive an appropriate description of losses.

Assuming the occurrence of the flood as a Poisson process [16; 17], the total life-cycle flood loss of the building $i$ during the time interval $\left[0, t_{\text {int }}\right]$ can be computed [24]

$$
L t_{i}\left(t_{\text {int }}\right)=\sum_{i=1}^{N\left(t_{\text {int }}\right)} l_{i}\left(t_{k}\right) \cdot e^{-\gamma t_{k}}
$$


where $t_{\text {int }}$ is investigated time interval; $N\left(t_{\text {int }}\right)$ is the number of hazard events that occur during the time interval; $l_{i}\left(t_{k}\right)$ is the expected annual hazard loss at time $t_{k}$; and $\gamma$ is the monetary discount rate. Based on [25], given the Poisson model with mean rate equal to $\lambda_{f}$, the time $t_{k}$ has a uniform distribution in $\left[0, t_{\text {int }}\right]$. Given $N\left(t_{\text {int }}\right)=\lambda_{f} \times t_{\text {int }}$, the total expected life-cycle loss and variance can be computed $[24 ; 25]$

$$
\begin{gathered}
E\left[L t_{i}\left(t_{\text {int }}\right)\right]=\frac{\lambda_{f} \cdot E\left(l_{i}\right)}{\gamma} \cdot\left(1-e^{-\gamma \cdot t_{\text {int }}}\right) \\
\operatorname{Var}\left[L t_{i}\left(t_{\text {int }}\right)\right]=\frac{\lambda_{f} \cdot E\left(l_{i}^{2}\right)}{2 \gamma} \cdot\left(1-e^{-2 \gamma \cdot t_{\text {int }}}\right) \\
E\left(l_{i}^{2}\right)=\left(E\left(l_{i}\right)\right)^{2}+\left(\sigma\left(l_{i}\right)\right)^{2}
\end{gathered}
$$

where $E\left(l_{i}\right)$ and $\sigma\left(l_{i}\right)$ is the expected value and standard deviation of annual loss $l_{i}$ of building $i$ given a flood event.

\section{Building Portfolio Loss}

The portfolio of structures considered herein is a group of residential buildings, which have similar characteristics, such as numbers of floors, material types, and geometrical pattern. The portfolio of the buildings located in the same neighborhood can be classified as one type of buildings (e.g., masonry building). The flowchart of building portfolio loss assessment under flood considering uncertainties and correlation is shown in Figure 2. The annual total loss associated with a spatially-distributed building portfolio under a given flood event is:

$$
R L=\sum_{i=i}^{n_{b u}} l_{i}
$$

where $n_{b u}$ is the number of buildings within the investigated portfolio.

As indicated in Eq. (12), the expected loss of the investigated building portfolio is the sum of the expected losses for each building. Buildings within a portfolio are similar and correlated 
considering their basic characteristics, such as the number of floors, material types, and geometrical pattern. Additionally, affected by the same flooding, the flood intensities at the location of the buildings are also correlated. Consequently, the losses associated with the buildings within the portfolio are correlated. Overall, the correlations among the performance of spatially distributed buildings are stronger due to the shared effects from the flood event and similarities in structural performance.

The variance of the sum of the loss of the portfolio of buildings depends not only on the expected value of total loss but also on the variance and the correlation among the losses. Considering the correlation effects, the variance of the annual loss of the building portfolio under the flood event is expressed as

$$
\left.\operatorname{Var}(R L)=\sum_{i=i}^{n_{b u}} \operatorname{Var}\left(l_{i}\right)+2 \cdot \sum_{i=1, i<j}^{n_{b u}} \sum_{j}^{n_{b u}} \rho\left(l_{i}, l_{j}\right) \cdot \sqrt{\operatorname{Var}\left(l_{i}\right) \cdot \operatorname{Var}\left(l_{j}\right.}\right)
$$

where $\rho\left(l_{i}, l_{j}\right)$ is the correlation coefficient between the annual flood loss of buildings $i$ and $j$ under the given flood event, and $\operatorname{Var}\left(l_{i}\right)$ and $\operatorname{Var}\left(l_{j}\right)$ are the variances of the annual loss of the building $i$ and $j$, respectively. By using Eq. (13), the variance of the total annual loss can be computed. With incomplete information on building configuration within a portfolio, the uncertainty may change.

Similarly, given the annual loss of the portfolio of buildings under a given flood event, the mean and variance life-cycle cost of a building portfolio can be calculated as

$$
\begin{gathered}
E\left[L C C_{B P}\left(t_{\mathrm{int}}\right)\right]=\frac{\lambda_{f} \cdot E(R L)}{\gamma} \cdot\left(1-e^{-\gamma \cdot t_{\mathrm{int}}}\right) \\
\operatorname{Var}\left[L C C_{B P}\left(t_{\mathrm{int}}\right)\right]=\frac{\lambda_{f} \cdot E\left(R L^{2}\right)}{2 \gamma} \cdot\left(1-e^{-2 \gamma \cdot t_{\mathrm{int}}}\right)
\end{gathered}
$$


Considering the uncertainties within the life-cycle cost analysis, the probability of exceedance of life-cycle cost during a certain time interval can be estimated. This information can aid the decision making process with respect to the hazard mitigation strategy.

\section{Probabilistic Cost-Benefit Analysis}

Cost-benefit analysis is a commonly used method to compare the cost and benefit of different hazard mitigation strategies over an investigated time interval. Herein, cost-benefit analysis is adopted to support the flood hazard mitigation procedure of portfolios of buildings under different retrofit actions in a life-cycle context. Federal Emergency Management Agency (FEMA) [26] proposed a retrofit guide for homeowners to protect the damage of buildings from flood. Retrofit actions can be adopted to make changes to the existing buildings and protect them from the flooding effects. The common retrofit methods for the buildings under flood are elevation, relocation, and demolition [26]. Among these retrofit methods, elevation is the most common used to lift the structure by building a new foundation or extending the existing foundation. Elevation actions are as follows: (a) separating the building from the foundation, (b) constructing a new and higher foundation, and (c) reattaching the building to the new foundation [26]. Heavyduty jacks are used to lift the building and cribbing is used to support the building. By elevation, the flood depth would be reduced and the structural performance under the given reduced flood depth associated with the retrofit action (e.g., elevation) can be assessed.

Quantifying the relationship between the retrofit actions and the retrofit cost can help the decision regarding the hazard mitigation procedure. The investigated hazard scenarios, time interval, and structural performance under retrofit actions are considered within the cost-benefit analysis process. The flowchart of the cost-benefit analysis of flood mitigation strategy of a single building is indicated in Figure 3(a). In order to perform cost-benefit analysis, the 
probabilistic benefit should be computed firstly. The benefits are related to uncertainties because they depend on the occurrence of a natural disaster and consequences of structural failure. The cumulative life-cycle cost associated with flood loss of an investigated single building with and without retrofit action can be computed using Eqs. (9) and (10). Then, the economic benefit of hazard mitigation actions of the investigated building $i$ can be expressed as

$$
B_{s b i}=L t_{s b i, N R}-L t_{s b i, R}
$$

where $L t_{s b i, N R}$ and $L t_{s b i, R}$ are the life-cycle cost without and with retrofit actions of the investigated single building $i$, respectively.

Similarly, the benefit associated with the retrofit plan of a portfolio of buildings can be computed. In this paper, the probabilistic benefit-cost ratio is introduced to directly compare the benefit and cost of a retrofit action and aid the decision making associated with flood hazard mitigation. The benefit-cost ratio can be calculated as

$$
\begin{gathered}
C B_{B P}=\left(L C C_{B P, N R}-L C C_{B P, W R}\right) / C_{r, B P} \\
C_{r, B P}=\sum_{i=0}^{n_{b u}} c_{r, b i}
\end{gathered}
$$

where $L C C_{B P, N R}$ and $L C C_{B P, W R}$ are the life-cycle cost of building portfolio under flood effects without and with retrofit, respectively; $C_{r, B P}$ is the total retrofit cost of the building portfolio; and $c_{r, b i}$ is the retrofit cost associated with building $i$. The benefit-cost ratio essentially quantifies the effectiveness of a retrofit plan. Values less than 1 indicate that retrofit is not cost-effective while values greater than 1 denote that it is beneficial to perform retrofit.

The expected value and standard deviation of life-cycle cost of the portfolio of buildings under flood can be computed using Eqs. (14) and (15). Given the mean value, the standard deviation of the life-cycle cost, and correlation among the cases with and without retrofit actions, 
the expected value and standard deviation of the benefit-cost ratio can be computed. Furthermore, given the random variables associated with the benefit-cost ratio, the probability of exceedance of this ratio can be obtained. The probabilistic cost-benefit analysis of the retrofit actions associated with portfolios of buildings is qualitatively illustrated in Figure 3(b) considering probability density functions (PDFs) of various costs.

\section{Illustrative Example}

The proposed approach is illustrated on a portfolio of residential buildings located in Pinellas County, Florida, as indicated in Figure 4(a). The portfolio of structures considered herein is a group of masonry residential buildings, which have similar characteristics, such as the number of floors, material types, and geometrical pattern. The unreinforced single story masonry building is the most common residential building type. Herein, the portfolio of the residential buildings located in the same neighborhood is classified as one class of buildings. The annual loss of the single building and building portfolio under a given flood event is investigated. Additionally, the probabilistic life-cycle cost and cost-benefit analysis in a life-cycle context are investigated to aid the decision making process on the hazard mitigation strategy.

\section{Building Damage Assessment}

Floods generally originate from overflowing water or streams. Coastal floods occur on the shores of lakes and seas due to heavy rainfall and/or an atmospheric low-pressure system. Based on the historical data, the flood frequency analysis can be conducted to determine the maximum peak flood associated with a given return period. Herein, the occurrence model of the flood is assumed a Poisson process, with an annual flood occurrence rate of 0.01 . In order to compute the building performance under flood, the flood characteristics (i.e., depth and velocity) should be identified. Based on the location of the building, the flood depth associated with a given flood event can be 
derived from existing data by fitting a PDF. Then, Monte Carlo simulation can be used to generate the probabilistic parameters. The flood scenario depends on many factors, such as the topography of drainage basin, intensity of rainfall, and types of soil and land use. The peak flow associated with different return periods of the flood can be determined based on historical data. Together with the topographic map of the investigated region, the hazard intensity associated with the water height and velocity for a given return period can be obtained and incorporated within the structural performance assessment process. In this paper, the yearly maximum flood depth associated with the investigated flood is assumed to follow a lognormal distribution, with a mean of $2 \mathrm{~m}$ and a standard deviation of $0.4 \mathrm{~m}$. Herein, the hazard intensity and scenarios are selected for illustrative purpose. Given more information, the data for the flood scenario can be easily updated. Given the flood depth $(\mathrm{m})$, the velocity of the flood $(\mathrm{m} / \mathrm{s})$ is computed using the following equation [1]

$$
V=0.3048 \cdot(105.6 \cdot h)^{0.5}
$$

The flooding actions on a single building considered herein are: hydrostatic pressure, hydrodynamic pressure, and debris impacts as indicated in Eqs. (1) to (6). The parameters used are shown in Table 1. The structural analysis of the wall under the hydrostatic and hydrodynamic pressures is conducted based on Roos [12]. Accordingly, the maximum load effect bending moment is computed. The PDF of this moment is indicated in Figure 5(a), with a mean of $2.05 \times$ $10^{4} \mathrm{~N} \cdot \mathrm{m}$ and a standard deviation of $1.13 \times 10^{4} \mathrm{~N} \cdot \mathrm{m}$.

In this paper, the failure of walls under a flood event is investigated by considering the applied bending moments. The failure mechanism of concrete or masonry buildings can be analyzed using different computational methods, such FEM analysis [19], yielding line analysis [22], and structural analysis [12]. The failure mode proposed by Roos [12] is adopted in this 
paper to investigate the performance of an unreinforced masonry building under hydrostatic and hydrodynamic pressures. The wall can crack and collapse under the hydrostatic, hydrodynamic, and debris effects. For example, if the bending moment capacity associated with cracking of the wall is smaller than the applied loading bending moment, then cracks would appear and serviceability limit state will be reached. The four damage states associated with the wall failure considered in this paper are none, cracking, partial collapse, and collapse. The bending moment associated with cracking and ultimate capacity could be computed, respectively, as [12; 15]

$$
\begin{aligned}
& M_{c}=\frac{\left(f_{t}+\sigma_{c}\right)}{6} w \cdot t_{w}{ }^{2} \\
& M_{u}=\frac{\left(f_{c}-\sigma_{c}\right)}{6} w \cdot t_{w}{ }^{2}
\end{aligned}
$$

where $\sigma_{c}$ is the compression stress $\left(N / m^{2}\right) ; w$ is the width $(m) ; t_{w}$ is the thickness of the wall $(m)$; $f_{c}$ is the compression strength $\left(\mathrm{N} / \mathrm{m}^{2}\right)$; and $f_{t}$ is the tensile strength $\left(\mathrm{N} / \mathrm{m}^{2}\right)$. The strength of the masonry depends on many factors, such as type of mortar, mortar materials, and the workmanship. The flexural tensile strength is an important parameter for unreinforced masonry and is related to the bond strength of masonry in flexure. Given the loading moment $M_{f}$ induced by the flood, the performance functions associate with cracking, partial, and total collapse can be expressed, respectively, as [15]

$$
\begin{gathered}
g_{c r a}=M_{c}-M_{f} \\
g_{p c}=M_{u}-M_{f} \\
g_{c o l}=1.2 M_{u}-M_{f}
\end{gathered}
$$

The factor 1.2 in Eq. (24) is adopted to consider the effects of plasticity and horizontal load transfer, which are not included in the structural analysis process [15]. In order to compute the probability of structural failure under flood, the bending capacity has to be computed. The 
bending moment capacity associated with cracking and ultimate failure are calculated via Eqs. (20) and (21). The relevant parameters are indicated in Table 1. The PDF associated with the ultimate bending moment is shown in Figure 5 (b). Subsequently, given the input with respect to the load effects and capacity, the probability of failure of the investigated single building under the investigated flooding effects is obtained. Similarly, based on Eqs. (22) to (24), the probabilities of the investigated building for all considered damage states (none, cracking, partial collapse, and collapse) are computed.

\section{Loss Assessment of Single Building}

Based on the building's performance, the consequence and loss in monetary terms are computed. Given the probabilities of the building being in different performance levels under a given flood, the annual repair loss is computed using Eq. (7). The cost of the investigated target single-family house is taken as $C_{b}=200,000$ US\$ [28] and it is assumed that all buildings within the portfolio have the same cost. The repair cost ratio associated with cracking, partial, and total collapse is $0.33,067$, and 1.0, respectively [15]. The load effect considering the debris effects is computed using Eqs. (5) and (6). Then, based on Eq. (7), the expected annual repair loss with and without

considering debris effects is $7.07 \times 10^{4}$ and $6.03 \times 10^{4} \mathrm{US} \$$, respectively. As indicated, the debris has a great effect on the building performance under flooding effects and affects the annual loss.

The life-cycle cost of the investigated building under the flood effects is also investigated. The expected and variance of the life-cycle cost are computed using Eqs. (9) - (11). In this paper, the monetary discount rate $\gamma$ assumed is $2 \%$. The expected value and standard deviation of total life-cycle loss of the investigated building under different time intervals are shown in Figure 6. As indicated, the investigated service life has a large effect on both the expected and standard deviation of the life-cycle cost of the investigated building under flood. Additionally, the effect 
of monetary discount rate on the expected life-cycle cost is investigated in this paper. As shown in Figure 7, the monetary discount rate can affect the expected value of the life-cycle cost significantly.

\section{Loss of Portfolio of Buildings}

The regional loss of the portfolio of buildings under the given flood event considering uncertainty and correlation effects is computed in this section. The detailed spatial distribution and correlation associated with the hydrodynamic pressure among the buildings is not considered herein. The correlation among the building loss within the investigated regions is assumed to cover both spatial and temporal correlation effects. The residential buildings located in the same neighborhood have similar characteristics (e.g., material types and geometrical pattern). The portfolio of the buildings investigated is classified as one class of buildings. Figure 4(b) aims to show the configuration of the class of the buildings within the investigated region. All these buildings in this neighborhood have similar characteristics. For instance, number of storey, material, and geometrical patterns. There are 90 single buildings located in the investigated area indicated in Figure 4 (a). The expected value of the regional loss is the sum of the loss associated with all the buildings located in the investigated region and is computed using Eq. (12).

The variance of annual regional loss of the portfolio under the investigated flood scenario considering different correlation coefficients is computed using Eq. (13). The relevant results are shown in Figure 8(a). Given $\gamma=2 \%$ and $t_{i n t}=75$ years, increase associated with the standard deviation of the annual regional loss is consistent with the correlation coefficient. Additionally, the effects of uncertainty associated with building cost are also investigated. Herein, the coefficient of variation of the building $\operatorname{cost} C_{b i}$ is assumed 0.3 as a lognormal random variable [15]. As illustrated in Figure 8(a), the uncertainty associated with building cost has a more 
significant effect on the standard deviation of the annual building portfolio. Overall, neglecting correlations can lead to underestimation of the standard deviation of losses.

Given the annual loss of the portfolio of buildings and occurrence model of the flood, the life-cycle cost of the portfolio is computed using Eqs. (14) and (15). The standard deviation of the life-cycle cost of the building portfolio is also investigated in this paper and is presented in Figure 8(b). As it can be easily noticed, this standard deviation increases with the correlation coefficient.

\section{Probabilistic Life-Cycle Cost-Benefit Analysis}

The cost-benefit analysis is adopted to investigate and compare the cost-effectiveness associated with different retrofit actions applied to buildings. Generally, the retrofit cost is related to the material and installation cost. Given the specific retrofit action, the cost and benefit associated with a given retrofit action are obtained. The flood mitigation technique investigated herein is elevation of buildings. The two elevation heights $h_{\text {ele }}$ considered are $0.5 \mathrm{~m}$ and $0.25 \mathrm{~m}$. By elevation, the height of the flood is reduced by $h_{\text {ele }}$ and the flood effects on the building are reduced. Then, the probabilities of the building being in different performance levels are obtained. The benefit associated with the elevation retrofit action on a single building is computed by using Eq. (16). The benefit associated with hazard mitigation strategy on the investigated building considering different mitigation actions is shown in Figure 9.

The effects of retrofit actions on the life-cycle cost of building portfolio are also investigated. Herein, different retrofit plans associated with the portfolio of buildings are considered. The five cases considered are associated with the number of the buildings $N_{r e t}$ that are retrofitted. Herein, $N_{\text {ret }}$ equals to $0,23,45,68$, and 90 among the portfolio of 90 buildings. Given $t_{\text {int }}=75$ years and $\gamma=0.02$, the effects of correlation coefficient on the standard deviation of the life-cycle cost of 
the building portfolio under these five different retrofit plans are shown in Figure 10(a). As indicated, given an increase in the number of retrofitted buildings, the standard deviation of the life-cycle cost of the investigated portfolio decreases. Additionally, the standard deviations of the life-cycle cost under different service lifetimes are shown in Figure 10(b).

Given the cost of retrofit actions, the benefit-cost ratio associated with different retrofit plans of the building portfolio is investigated using Eq. (17). Herein, the retrofit cost is assumed 5\% of the cost of the building; it is also assumed that the life-cycle cost of portfolio follows lognormal distribution with the mean value and dispersion identified in Eqs. (14) and (15). Given the mean value and standard deviation of the life-cycle cost of building portfolio with and without retrofit and the retrofit cost, the benefit-cost ratio is computed using Eq. (17). Then, the probability of exceedance of benefit-cost ratio of the portfolio for different service life periods is shown in Figure 11(a). It is evident that the benefit-cost ratio is increasing with the service life. Thus, the service life has a significant effect on the decision making regarding the flood retrofit plans of the portfolio of buildings. The probability of exceedance of benefit-cost ratio considering different number of buildings and service life is shown in Figure 11(b). Additionally, the effects of monetary discount ratio and cost of retrofit plans on the benefit-cost ratio are also investigated and results are presented in Figure 12(a) and (b). As shown, the retrofit cost has a large effect on the probability of exceedance of the benefit-cost ratio.

The effect of the number of buildings within a portfolio on the benefit-cost ratio is also investigated. With incomplete information of building configuration within a portfolio, the uncertainty may change. If more buildings are considered in the assessment procedure, the uncertainties will increase. Herein, the coefficient of variation of the life-cycle cost of the investigated building portfolio is assumed to increase with the number of the buildings under 
investigation. For this reason, the amplification factor $a f_{u}$ is introduced, and it is assumed that the standard deviation of the life-cycle cost of the portfolio of buildings is amplified by the factor $a f_{u}$, while the expected value remains the same. Relevant results are shown in Figure 12(c), in which it can be noticed that the probability of exceedance of benefit-cost ratio when the number of buildings increases can be smaller or larger depending on the amplification factor. Thus, the number of buildings within a portfolio and the uncertainty associated with life-cycle cost of this portfolio affect the decision-making for hazard mitigation plans.

\section{Conclusions}

In this paper, the regional loss assessment of building portfolios is investigated in a life-cycle context considering uncertainties and correlation effects. The probabilistic cost-benefit analysis associated with retrofit actions is also investigated. The probability of exceedance of the lifecycle loss and benefit-cost ratio under a given flood scenario is calculated. The presented approach is illustrated on a portfolio of residential unreinforced single story masonry buildings located in Pinellas County, Florida.

The following conclusions are obtained:

1. The mean and standard deviation of the life-cycle cost of buildings under flood effects are sensitive to the investigated time interval and monetary discount rate. These parameters should be carefully evaluated within the life-cycle performance assessment process. The expected value of life-cycle cost of a single building associated with 100 years time interval is about 2.2 times of that associated with 25 years time interval.

2. Given the investigated flood scenario, the annual expected loss of the investigated building taking into account the debris effect is about $20 \%$ larger than that without considering this effect. 
3. As the life-cycle cost has a high dispersion, it is of paramount importance to consider both the mean and standard deviation of the life-cycle cost associated with a building portfolio within the hazard mitigation process. A decision based only on the expected value can not lead to an optimal solution.

4. The benefit associated with retrofit actions increases as the investigated time interval increases. Based on the results presented in this paper, the expected benefit associated with 100 years time interval is almost 2.3 times of that associated with the 25 years time interval. Regarding the decision making for hazard mitigation, it is more economic to consider the effects of retrofit actions in a long time interval and different decisions can result with respect to different time intervals. Thus, both short and long-term benefit and budget constraints should be considered. Furthermore, regarding the benefit-cost analysis, as there are large uncertainties associated with flood occurrence and its intensity, a probabilistic benefit-cost analysis is needed. Based on this study, as the uncertainty increases with the number of the buildings under investigation, different decisions regarding retrofit plans are obtained by considering the probabilistic benefitcost ratio. This aspect also demonstrates the importance of incorporating uncertainties within the hazard mitigation procedure.

5. Correlation effects associated with loss of buildings have a substantial effect on the variance of the annual loss and life-cycle cost. Under the given investigated scenario, the standard deviation of the annual loss of the buildings associated with the fully correlated case is about 7.3 times of that associated with neglecting correlation. The effects of correlation among the building losses decrease with the increase of the investigated time interval. 
6. Based on the results presented in this paper, the retrofit decision with respect to a single building depends on the number of the buildings under investigation and correlation effects. By providing the value of the probability of exceedance of benefit-cost ratio, the decision maker can choose the retrofit types and proportion of the buildings to be retrofitted to meet their needs. Overall, this approach can provide more information to the decision maker. This information can be used in design, maintenance, and retrofit optimization processes of civil infrastructure systems under extreme events.

\section{Acknowledgements}

The support from (a) the National Science Foundation (NSF) through grant CMMI-1537926, (b) the Commonwealth of Pennsylvania, Department of Community and Economic Development, through the Pennsylvania Infrastructure Technology Alliance (PITA), (c) the U.S. Federal Highway Administration (FHWA) Cooperative Agreement Award DTFH61-07-H-00040, and (d) the Office of Naval Research (ONR) Award N00014-16-1-2299 is gratefully acknowledged. The opinions and conclusions presented in this paper are those of the authors and do not necessarily reflect the views of the sponsoring organizations.

\section{References}

[1] FEMA (2014a). Guidance for flood risk analysis and mapping: Flood depth and analysis grids, 2014, Washington, D.C.

[2] Dutta, D. (2003). Flood disaster trends in Asia in the last 30 years. International Centre for Urban Safety Engineering. Institute of Industrial Science. University of Tokyo. ICUS/INCEDE Newsletter 3(1), 1-5.

[3] Douben, K. (2006). Characteristics of river floods and flooding: a global overview 1985-2003. Irrigation and Drainage, 55(S1), S9-S21.

[4] Cornell, C.A., and Krawinkler, H. (2000). Progress and challenges in seismic performance assessment. PEER Center News, 3, 1-3. 
[5] Van de Lindt, J., and Dao, T. (2009). Performance-based wind engineering for wood-frame buildings. J Struct Eng., 135, 169-177.

[6] Barbato, M., Petrini, F., Unnikrishnan, V.U., and Ciampoli, M. (2013). Performance-based hurricane engineering (PBHE) framework, Structural Safety, 45, 24-35.

[7] Dong, Y., and Frangopol, D.M. (2015). Performance-based seismic assessment of conventional and base-isolated steel buildings including environmental impact and resilience. Earthquake Engineering \& Structural Dynamics, 45(5), 739-756.

[8] Kreibich, H., Thieken, A.H., Petrow, T., Müller, M., and Merz, B. (2005) Flood loss reduction of private households due to building precautionary measures-lessons learned from the Elbe flood in August 2002. Nat Hazards Earth Syst Sci, 5, 117-126.

[9] Merz, B., Kreibich, H., Thieken, A., and Schmidtke, R. (2004). Estimation uncertainty of direct monetary flood damage to buildings. Natural Hazards and Earth System Sciences, 4, $153-163$.

[10] Scawthorn, C., Blais, N., Seligson, H., Tate, E., Chang, S., Mifflin, E., Thomas, W., Murphy, J., Jones, C., and Lawrence, M. (2006) HAZUS-MH flood loss estimation methodology. II: damage and loss assessment. Nat. Hazard Rev, 7(2), 72-81.

[11] Kreibich, H., Piroth, K., Seifert, I., Maiwald, H., Kunert, U., Schwarz, J., Merz, B., and Thieken, A.H. (2009). Is flow velocity a significant parameter in flood damage modelling? Nat Hazards Earth Syst Sci, 9, 1679-1692.

[12] Roos, W. (2003). Damage to buildings. TNO Bouw, Delft Cluster Publication DC1-233-9, Delft, Netherlands.

[13] Kelman, I. (2002) Physical flood vulnerability of residential properties in coastal, Eastern England. PhD Dissertation, University of Cambridge, Cambridge, UK.

[14] Mazzorana, B., Simoni, S., Scherer, C., Gems, B., Fuchs, S., and Keiler, M. (2014). A physical approach on flood risk vulnerability of buildings. Hydrol Earth Syst Sci, 18, 38173836.

[15] Custer, R., and Nishijima, K. (2015). Flood vulnerability assessment of residential buildings by explicit damage process modelling. Nat Hazards, 78, 461-496.

[16] FEMA (2007). Guidelines and specifications for flood hazard mapping Partners, Washington, D.C. 
[17] Gupta, R.S. (1989). Hydrology and Hydraulic Systems, Prentice Hall, Upper Saddle River, N. J.

[18] FEMA (2012). Engineering principles and practices for retrofitting flood-prone residential structures. FEMA P-259. Federal Emergency Management Agency. Washington D.C., US.

[19] De Risi, R., Jalayer, F., De Paola, F., Iervolino, I., Giugni, M., Topa, M.E., Mbuya, E., Kyessi, A., Manfredi, G., and Gasparini, P. (2013). Flood risk assessment for informal settlements. Nat Hazards, 69, 1003-1032.

[20] Xiao, S., and Li, H. (2013). Impact of flood on a simple masonry building. Journal of Performance of Constructed Facilities,27(5), 550-563.

[21] Nadal, N.C. (2007). Expected Flood Damage to Buildings in Riverine and Coastal Zones, University of Puerto, Rico, Puerto Rico.

[22] Kelman, I., and Spence, R. (2003). A limit analysis of unreinforced masonry failing under flood water pressures. Masonry International, 16(2), 51-61.

[23] Dong, Y., Frangopol, D.M., and Saydam, D. (2014). Sustainability of highway bridge networks under seismic hazard. Journal of Earthquake Engineering, 18(1), 41-66.

[24] Dong, Y. and Frangopol, D.M. (2016). Probabilistic time-dependent multihazard life-cycle assessment and resilience of bridges considering climate change. J. Perform. Constr. Facil. , 30(5), 04016034, 1-12.

[25] Yeo, G.L., and Cornell, C.A. (2005). Stochastic characterization and decision bases under time-dependent aftershock risk in performance-based earthquake engineering. PEER Report, University of California, Berkeley, CA.

[26] FEMA (2014). Homeowner's Guide to Retrofitting, 3rd Edition, FEMA P-312, Washington, D.C.

[27] Google Inc. (2016). Google Maps (maps.google.com), Google Inc., Menlo Park, CA (https://www.google.com/maps/@27.7109762,-82.6523227,284m/data=!3m1!1e3).

[28] Unnikrishnan, V.U., and Barbato, M. (2016). Performance-based comparison of different storm mitigation techniques for residential buildings. Journal of Structural Engineering, 142(6), 04016011, 1-12. 


\section{List of Figures}

Figure 1. Flowchart for the performance-based assessment of residential buildings under flood

Figure 2. Building portfolio loss assessment under flood considering uncertainties and correlation effects

Figure 3. (a) Flowchart for cost-benefit analysis associated with retrofit actions and (b) probabilistic cost-benefit analysis at portfolio levels including probability density functions of various costs

Figure 4. (a) Plan view of 90 residential buildings located in St. Petersburg, Pinellas County, FL based on the data provided in Google Inc. [27] and (b) building model under flood effects

Figure 5. Probability density function of (a) bending moment and (b) ultimate bending moment capacity

Figure 6. (a) Expected value and (b) standard deviation of the life-cycle cost of the building under flood with and without considering debris effects

Figure 7. Effect of monetary discount rate on the expected life-cycle cost of the investigated building

Figure 8. Standard deviation of (a) annual loss and (b) life-cycle cost of building portfolio under different correlation coefficients among the building losses with and without considering the uncertainty associated with repair cost

Figure 9. Expected benefit associated with different retrofit actions of single building in a lifecycle context

Figure 10. Standard deviation of life-cycle cost of building portfolio under different levels of retrofit actions considering (a) different correlation coefficients and (b) service life

Figure 11. Probability of exceedance of benefit-cost ratio of building portfolio under different (a) time intervals and (b) retrofit plans

Figure 12. Effects of (a) monetary discount rate $\gamma$, (b) retrofit cost $c r_{r e t}$, and (c) number of the buildings $n_{b u}$ on the probability of exceedance of benefit-cost ratio 


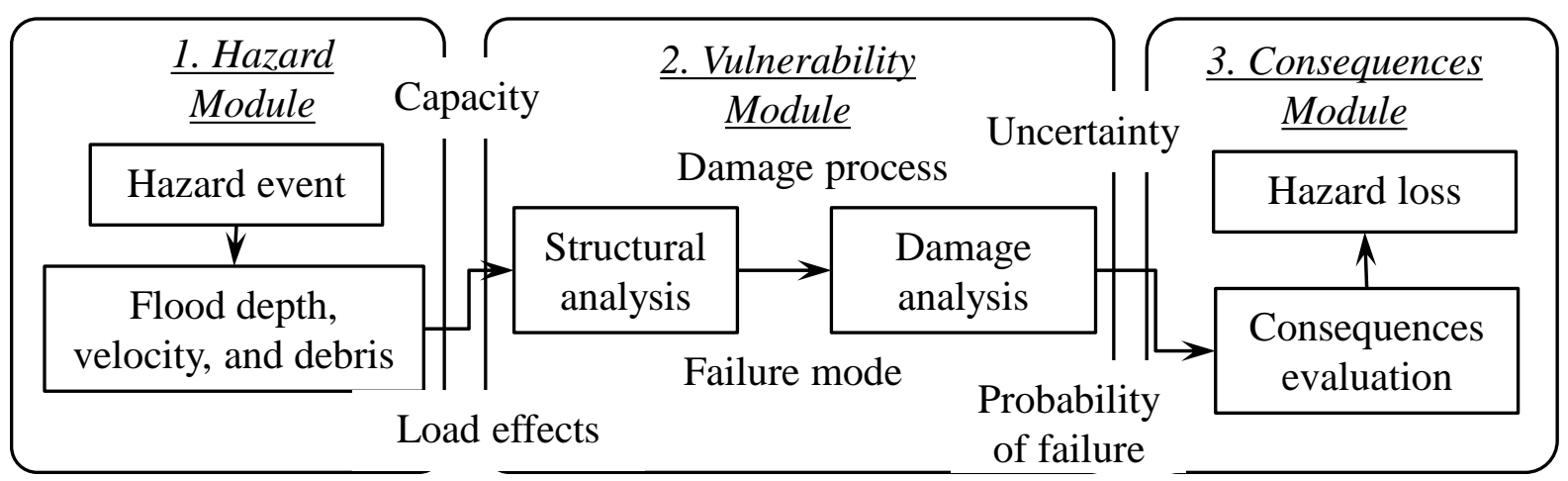




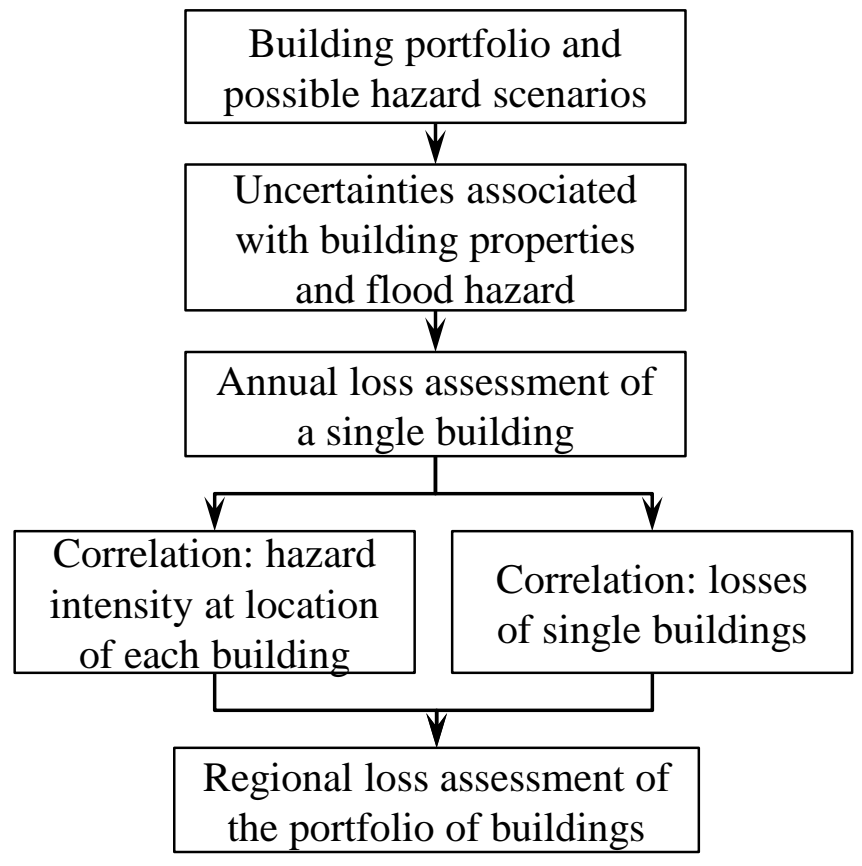


(a)
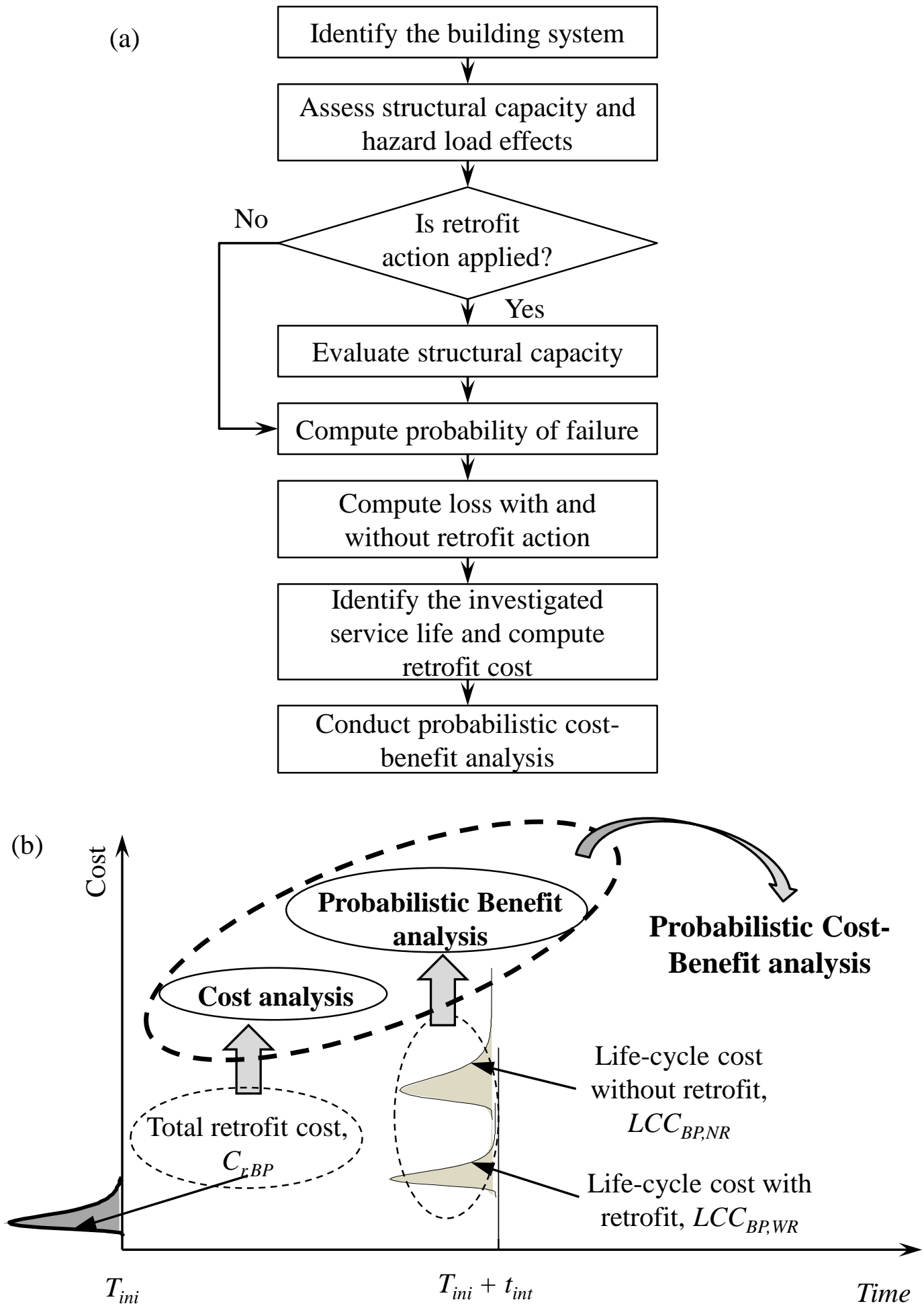
(a)

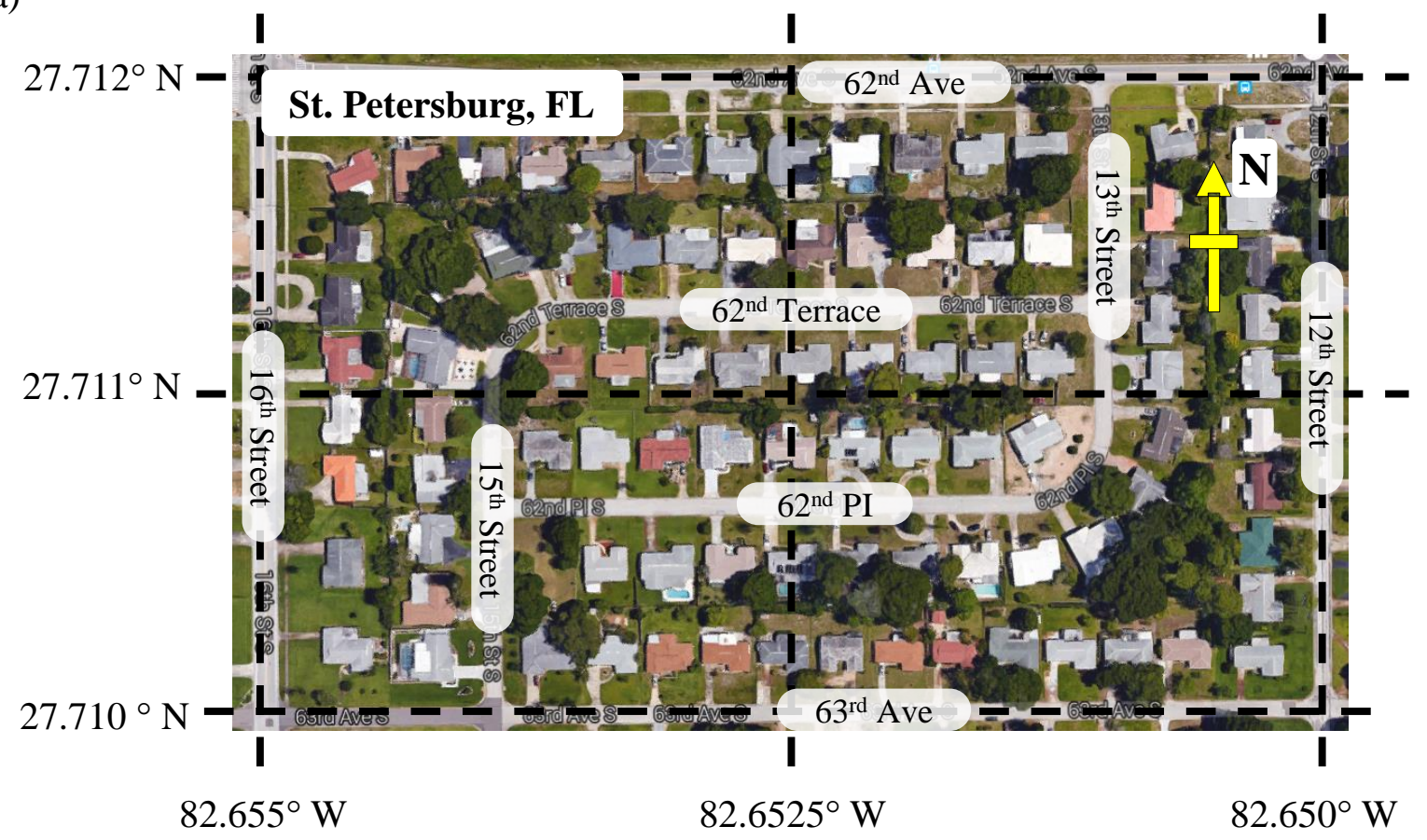

(b)

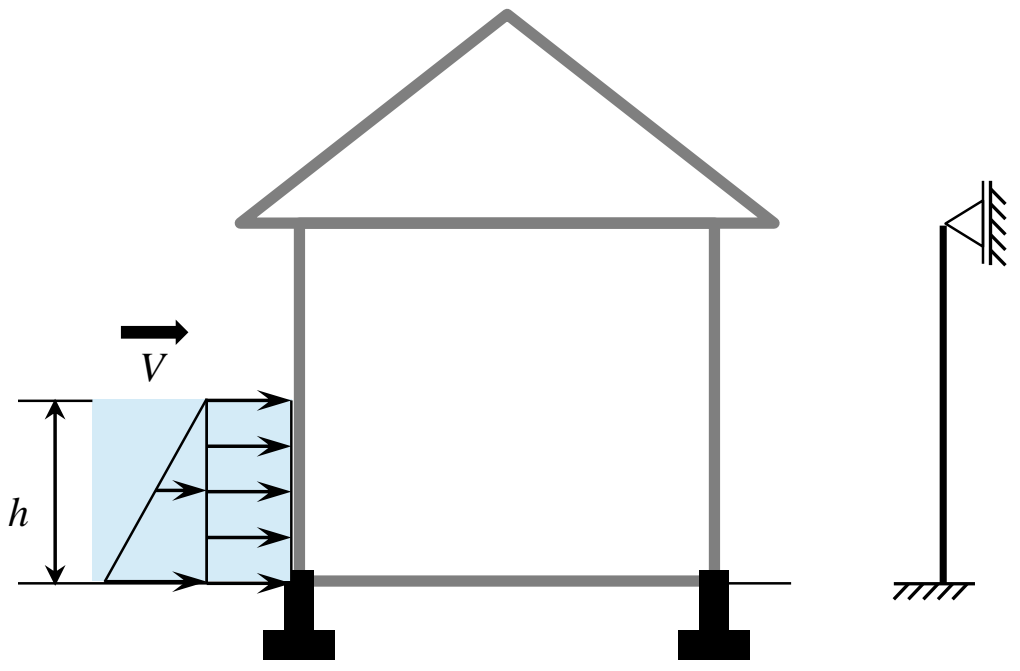


(a)

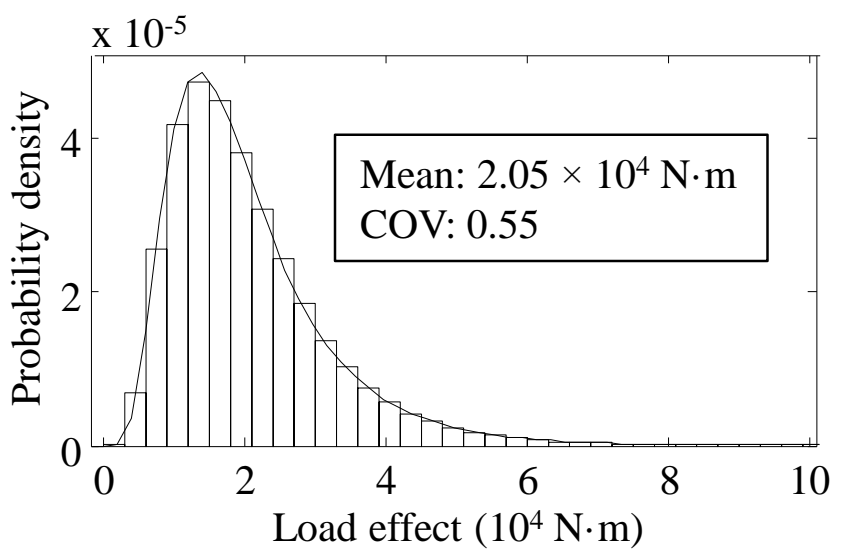

(b) $\quad \times 10^{-5}$

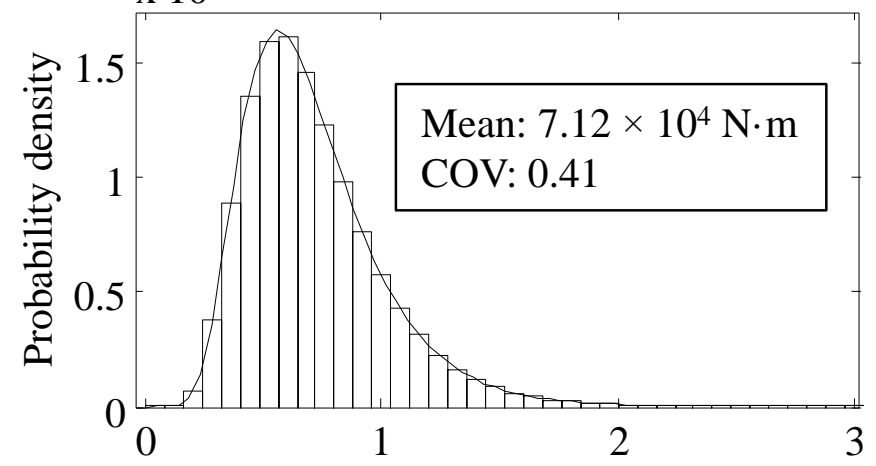

Ultimate bending moment capacity $\left(10^{5} \mathrm{~N} \cdot \mathrm{m}\right)$ 
(a)
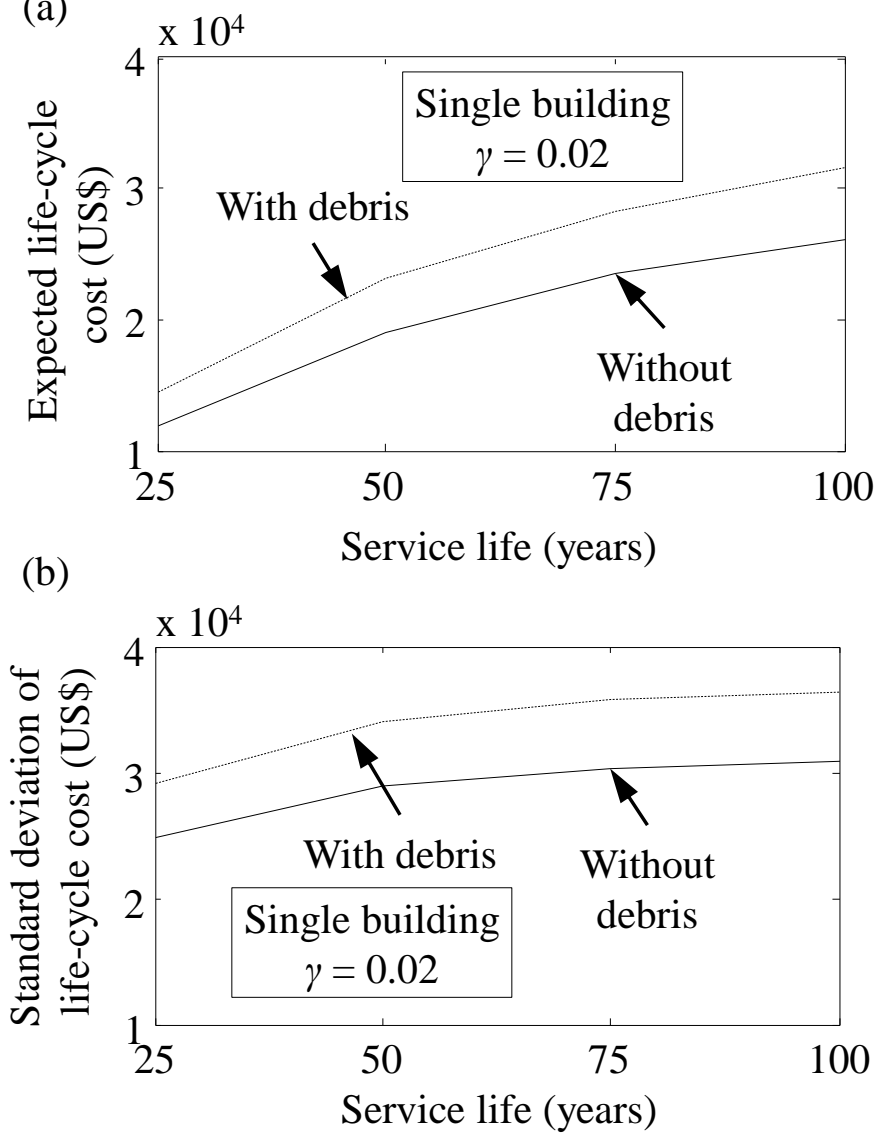


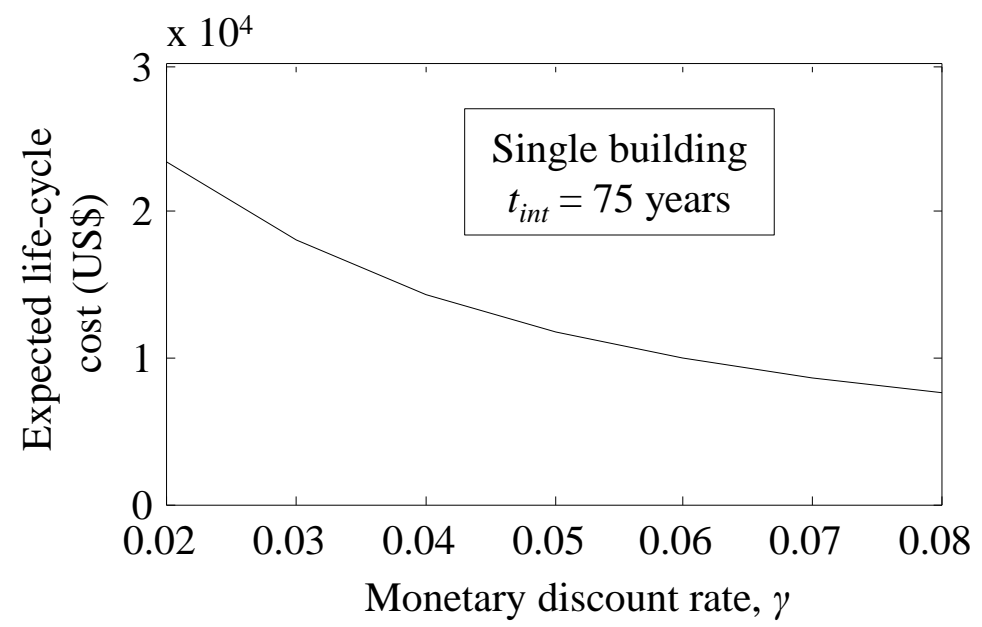




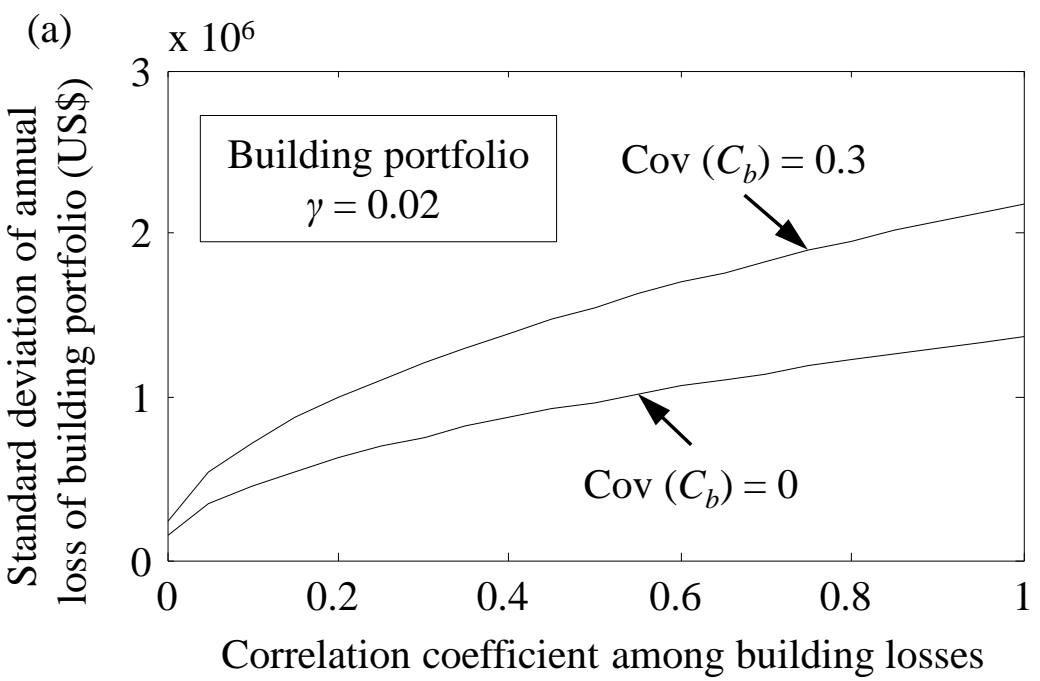

(b)

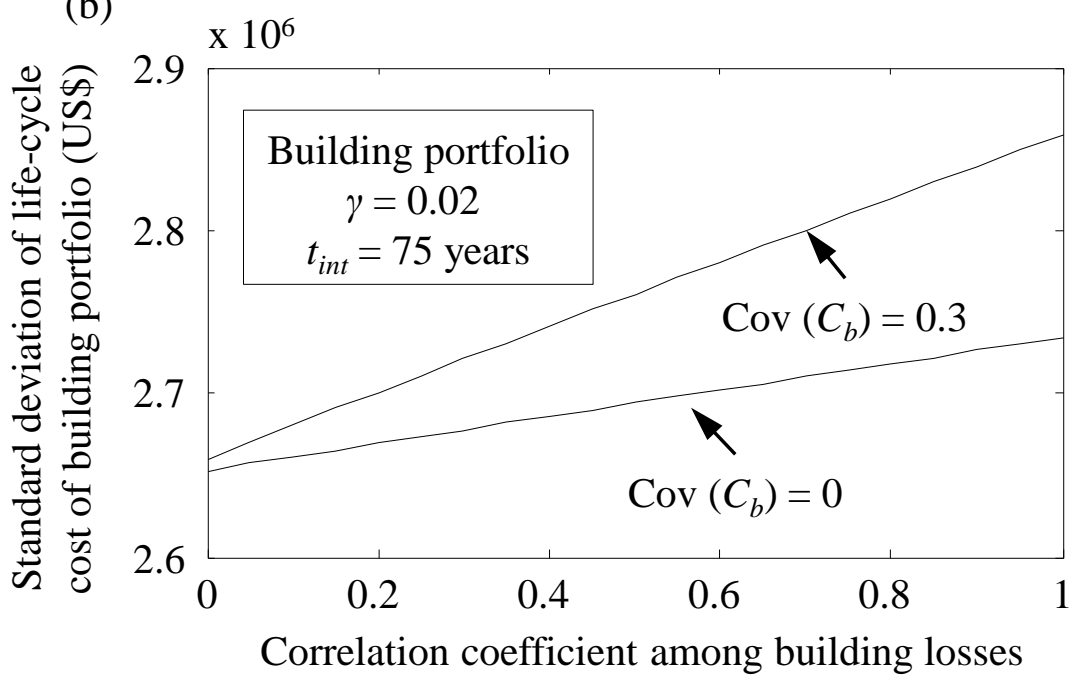




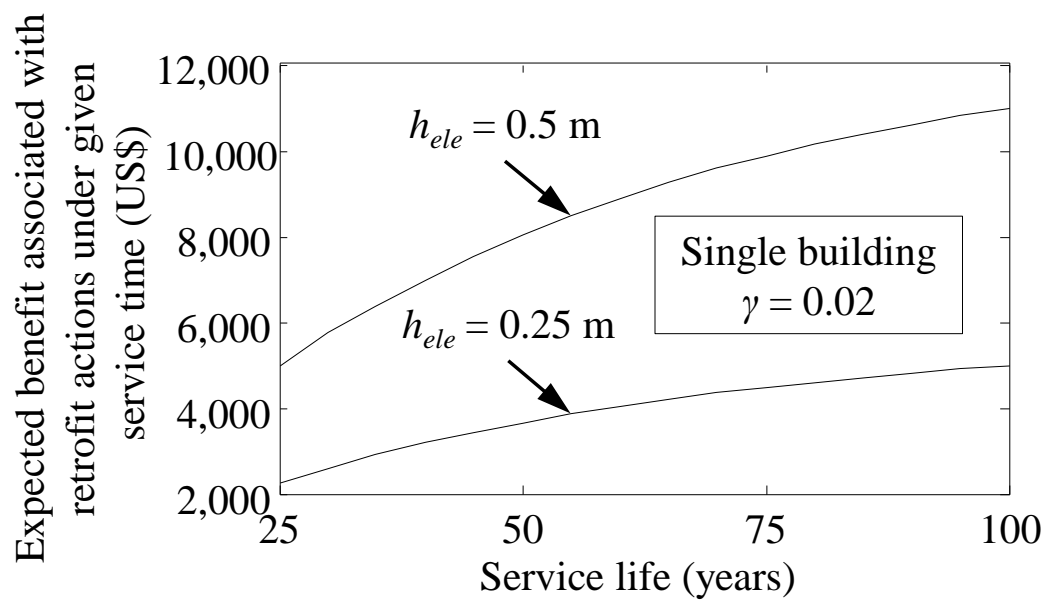


(a)

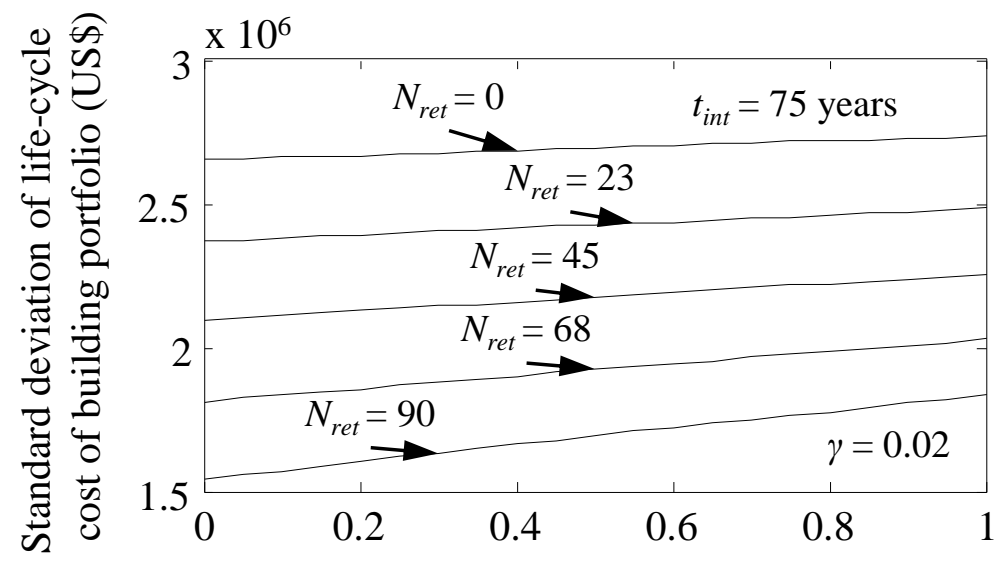

(b)

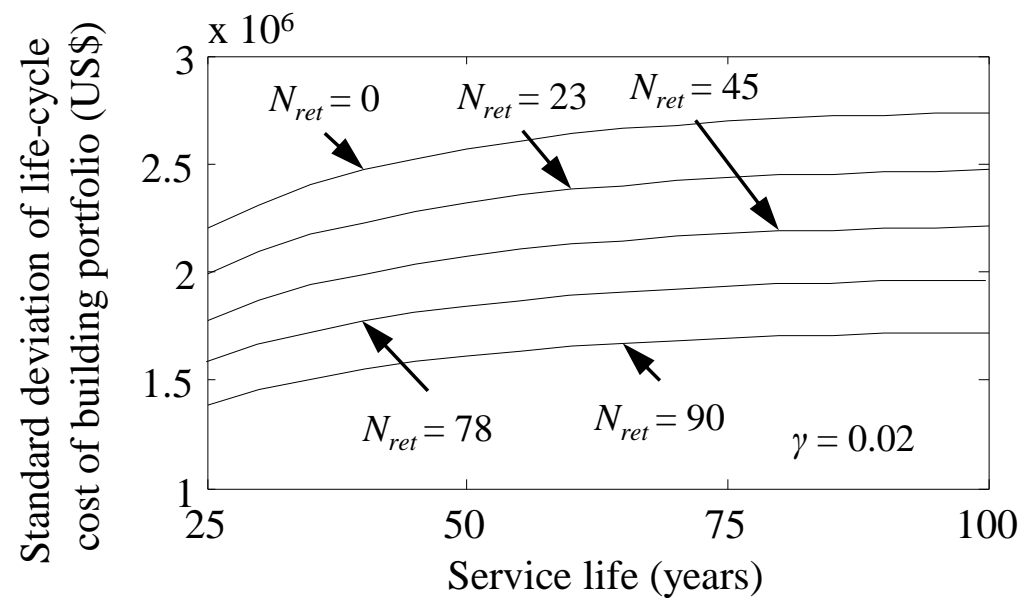


(a)

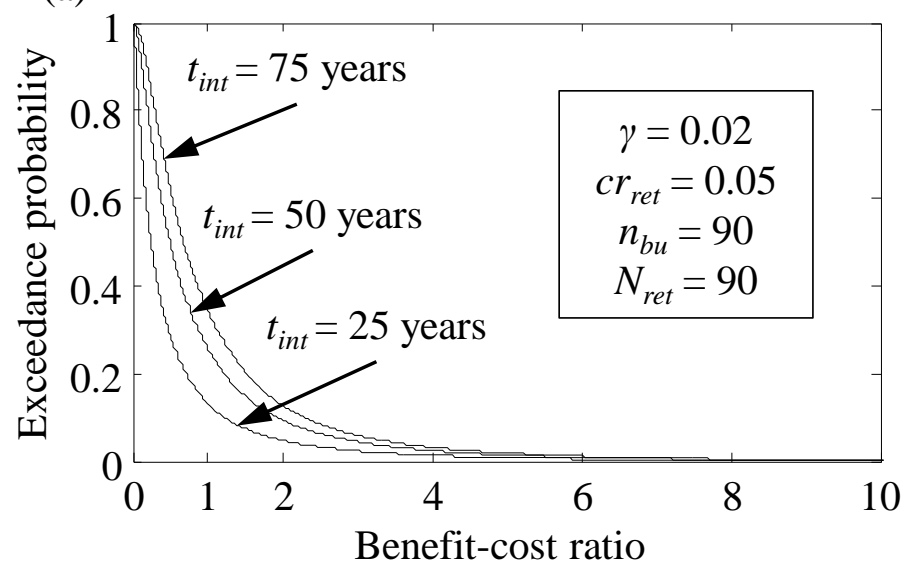

(b)

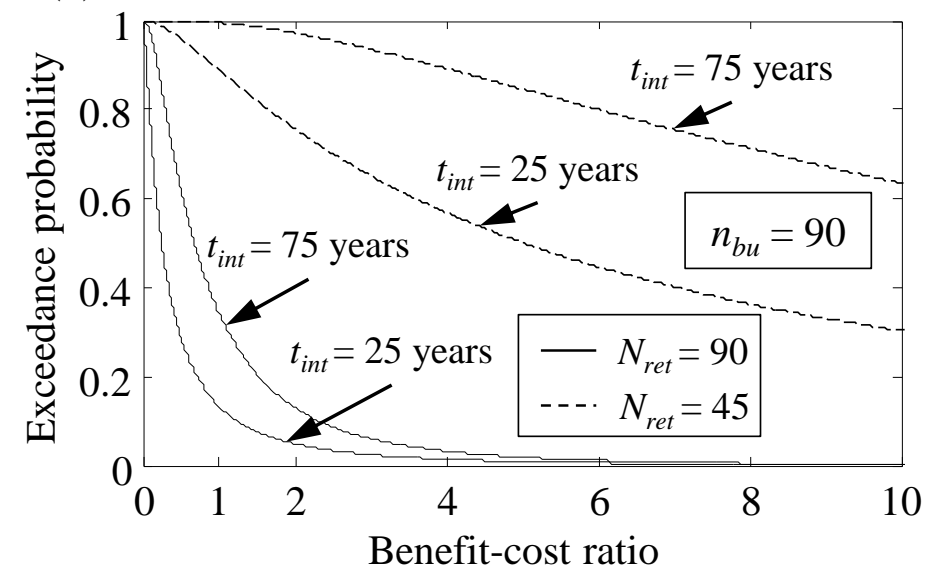



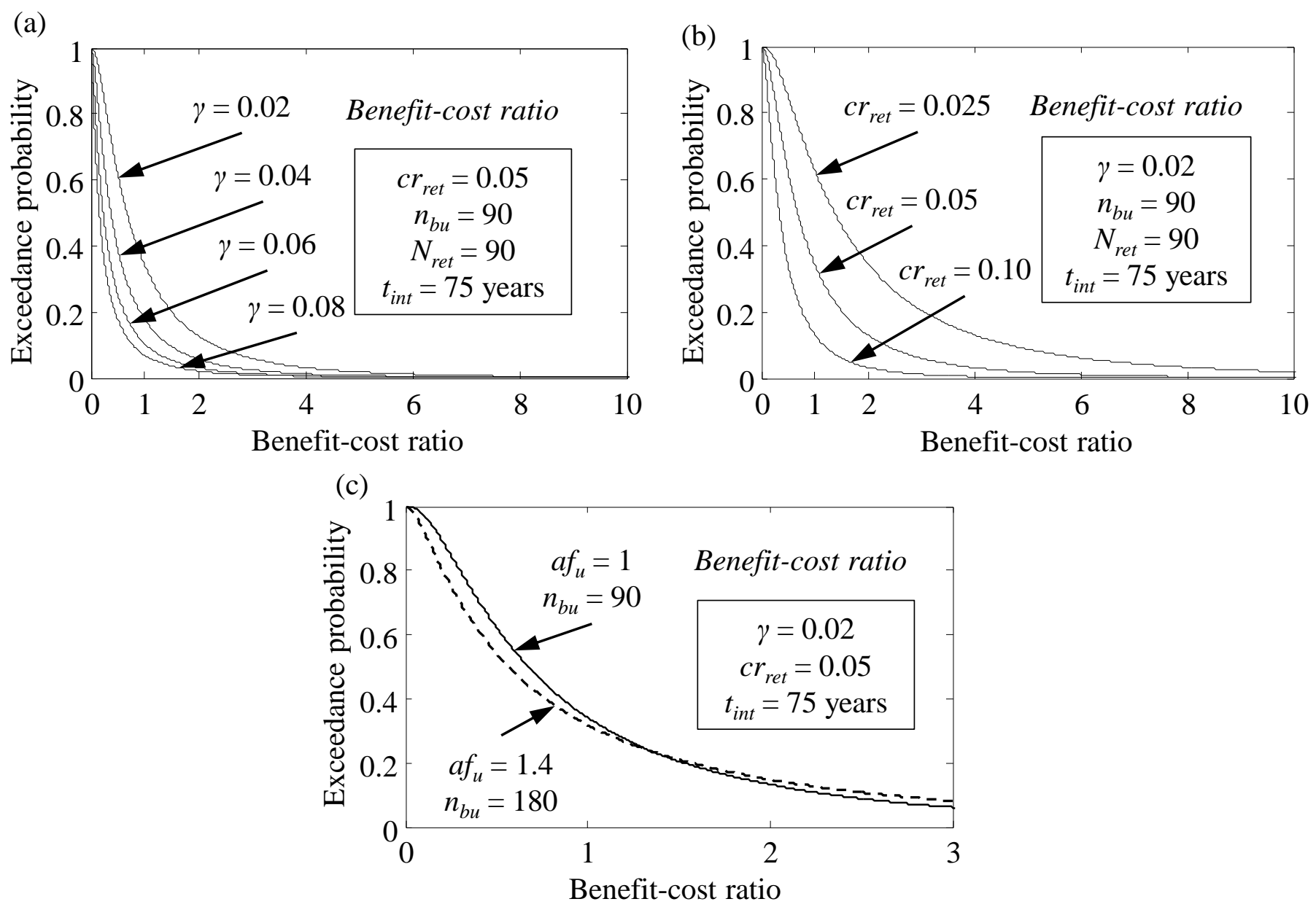


\section{List of Tables}

Table 1. Parameters of the random variables associated with the structural reliability and vulnerability analyses

\begin{tabular}{cccc}
\hline Parameters & Mean & COV & $\begin{array}{c}\text { Distribution } \\
\text { type }\end{array}$ \\
\hline Gravity acceleration, $g$ & $9.8 \mathrm{~m} / \mathrm{s}^{2}$ & DNA & DNA \\
Drag coefficient, $C_{d r a g}{ }^{\mathrm{a}}$ & 1 & 0.3 & LN \\
Mass density of water, $\rho_{w}$ & $1000 \mathrm{~kg} / \mathrm{m}^{3}$ & 0.2 & LN \\
Debris mass, $m_{d e}{ }^{\mathrm{c}}$ & $25 \mathrm{~kg}$ & 0.3 & LN \\
Young's modules of & $9 \times 10^{9} \mathrm{~Pa}$ & 0.2 & LN \\
debris ${ }^{\text {a }}{ }_{\text {Length of the debris }}{ }^{\mathrm{c}}$ & $1.5 \mathrm{~m}$ & 0.2 & LN \\
Width, $w$ & $1 \mathrm{~m}$ & 0.2 & LN \\
Wall height & $3 \mathrm{~m}$ & 0.2 & LN \\
Thickness of wall, $t_{w}$ & $0.23 \mathrm{~m}$ & 0.2 & LN \\
Compression strength, $f_{c}{ }^{\mathrm{b}}$ & $14 \mathrm{MPa}$ & 0.17 & LN \\
Tensile strength, $f_{t}{ }^{\mathrm{b}}$ & $0.24 \mathrm{MPa}$ & 0.3 & LN \\
\hline
\end{tabular}

DNA: does not apply; LN: lognormal distribution; COV = coefficient of variation;

${ }^{\mathrm{a}}$ : based on [12]; ${ }^{\mathrm{b}}$ : based on [15]; ${ }^{\mathrm{c}}$ : assumed. 